PERSPECTIVA TEOLÓGICA ADERE A UMA LICENÇA CREATIVE

COMMONS ATRIBUIÇÃO 4.0 INTERNACIONAL - (CC BY 4.0)

DOI: $10.20911 / 21768757 v 50 n 2 p 325 / 2018$

\title{
FRANCISCO E AS MIGRAÇÕES. UM OLHAR A PARTIR DAS MENSAGENS PARA O DIA MUNDIAL DO MIGRANTE E DO REFUGIADO (2014 A 2018)
}

Francis and Migration. A study on the Messages Addressed to the World Day of Migrants and Refugees (2014 to 2018)

Wagner Lopes Sanchez *

Estes nossos irmãos e irmãs [...] procuravam um lugar melhor para si $e$ para suas famílias, mas encontraram a morte. [...]

Quem é o responsável pelo sangue destes irmãos e irmãs? (Francisco, Lampedusa).

RESUMO: O artigo analisa as Mensagens do Papa Francisco para o Dia Mundial do Migrante e do Refugiado, de 2014 a 2018, e apresenta, a partir desses documentos, os principais aspectos de seu pensamento em relação às migrações. O pressuposto adotado é de que o Papa compreende os fluxos migratórios no contexto mais amplo do processo atual de globalização e que faz dos seus discursos uma oportunidade para denunciar as condições desumanas a que estão submetidos os migrantes e refugiados atuais. $\mathrm{O}$ artigo tem quatro partes: na primeira, examina a conjuntura global atual que provoca a condições necessárias para o desenvolvimento dos fluxos migratórios; na segunda, o texto examina a homília proferida pelo Papa na ilha de Lampedusa; na terceira, são analisadas as Mensagens objeto do artigo; por fim, na última parte, o texto apresenta os aspectos centrais do pensamento de Francisco sobre as migrações presentes nas Mensagens.

PALAVRAS-CHAVE: Papa Francisco. Igreja Católica. Migrações. Migrantes. Refugiados.

ABSTRACT: This article analyzes Pope Francis' Messages addressed to the World Day of Migrants and Refugees, from 2014 to 2018. Based on these documents, it

Instituto São Paulo de Estudos Superiores (ITESP), São Paulo, SP, Brasil. 
presents the main aspects of the Pope's thoughts on Migration. The assumption is that he understands migratory flows in the broader context of the current process of globalization, and that this makes his speeches an opportunity to denounce the inhuman conditions to which migrants and refugees are subjected today. The article has four parts: first, it examines the current global conjuncture that causes the necessary conditions for the development of migratory flows; secondly, the text examines the homily given by the Pope on the island of Lampedusa; third, the Messages on the topic are analyzed; finally, the text presents the central aspects of Francis' thoughts on Migration that are present in those Messages.

KEYWORDS: Pope Francis. Catholic Church. Migrations. Migrants. Refugees.

\section{Introdução}

$\mathrm{O}$

tema da mobilidade humana tem estado muito presente na imprensa e nas preocupações de muitas organizações da sociedade civil e de organismos governamentais envolvidos em políticas de gestão dos fluxos migratórios. As peculiaridades desses movimentos de parcelas significativas de pessoas que saem de seus países em razão de guerras, conflitos étnicos, perseguição política e perseguição religiosa, têm trazido à luz a face desumana das sociedades atuais. Os esforços realizados até aqui têm se mostrado insuficientes para atender minimamente às necessidades dos migrantes e refugiados.

A relevância do tema da mobilidade humana atual tem origem na própria gravidade da situação nos países de origem, nos trajetos percorridos por essas pessoas e nos lugares onde elas buscam abrigo e melhores condições de vida. É preciso elaborar diagnósticos muitos consistentes das situações que envolvem esse fenômeno, mas, sobretudo, é urgente abandonar a frieza das políticas e estratégias econômicas adotadas até aqui, e colocarmo-nos em sintonia com as necessidades e esperanças dessas pessoas.

Desde o início do seu ministério como bispo de Roma, Francisco tem colocado o tema das migrações no centro de suas preocupações. Seus pronunciamentos, de tom crítico, mostram o seu compromisso de denunciar as causas reais dos movimentos migratórios atuais e a forma como os países ricos se negam a resolver os problemas vividos por mais de 244 milhões de pessoas no mundo inteiro ${ }^{1}$. Os seus pronunciamentos, e as medidas que tem tomado, interpelam a própria Igreja Católica, exigindo que ela coloque os seus recursos a serviço da acolhida aos migrantes.

\footnotetext{
${ }^{1}$ Dado do início de 2016 (https://nacoesunidas.org/numero-de-migrantes-internacionais-chega-a-cerca-de-244-milhoes-revela-onu/. Acesso em 11-10-17).
} 
Este artigo tem por objetivo identificar as grandes características do pensamento do Papa Francisco ${ }^{2}$ sobre o tema das migrações através da análise das Mensagens para o Dia Mundial dos Migrantes e Refugiados, que é comemorado sempre no terceiro domingo do mês de janeiro. O pressuposto subjacente ao artigo é que o Papa compreende os fluxos migratórios no contexto mais amplo do processo de globalização econômica, e que faz dos seus discursos uma oportunidade para denunciar as condições desumanas a que estão submetidos os migrantes tanto nos países de origem, como nos países-destino.

Para Francisco, a Igreja Católica precisa contribuir de forma decisiva, seja através da acolhida aos migrantes, atenuando o seu sofrimento, seja através da denúncia das causas dos deslocamentos forçados e de medidas discriminatórias e marginalizadoras.

Consideramos que as Mensagens de Francisco para o Dia Mundial dos Migrantes e Refugiados apresentam-nos uma síntese das grandes ideias que esse Papa tem utilizado em seus discursos e documentos para manifestar as suas preocupações e o seu compromisso com a dura realidade vivida por migrantes e refugiados. Por isso, no nosso ponto de vista, a análise das Mensagens permite uma chave de leitura muito importante para entendermos o pensamento do Papa sobre os fluxos migratórios atuais.

\section{Um mundo de barreiras e os migrantes}

O mito da globalização atual (HIRST e THOMPSON, 1998) afirma que esta é um sistema aberto onde as fronteiras estão desaparecendo. No entanto, é preciso reconhecer que esse fenômeno, ao mesmo tempo em que modifica as políticas alfandegárias, em razão das decisões tomadas pelos países ricos no sentido de possibilitar que suas mercadorias circulem livremente entre os países, rejeita a possibilidade das pessoas circularem livremente. Do ponto de vista das pessoas que se veem forçadas a migrar, a ideia de que as fronteiras estão desaparecendo é falsa.

Agier, em sua reflexão sobre as migrações, apresenta-nos uma abordagem sobre as fronteiras justamente para mostrar que sem essa noção fica difícil entender hoje a indiferença e a rejeição aos migrantes. Como explica esse autor, a fronteira é ao mesmo tempo um lugar, um momento e uma situação que possibilita às pessoas viverem a sua relação com o mundo e com os outros (AGIER, 2015, p. 30). A ideia de fronteira, portanto, não é só geográfica e envolve também outras dimensões, mas, de qualquer forma,

${ }^{2}$ Uma boa apresentação das principais ideias do pensamento de Francisco pode ser é encontrada em Emilce Cuda, Para ler a Francisco. Teología, ética e política. 
ela envolve sempre o outro que está a nos desafiar como alguém que está próximo de nós - mesmo quando está distante - e que quer compartilhar o mesmo espaço, a mesma realidade.

A afirmação de que a globalização rompe com as fronteiras é muito contraditória justamente porque favorece a circulação de mercadorias, mas bloqueia a circulação de pessoas em condição de migração, como estamos presenciando.

A construção de muros não tem muito a ver com as fronteiras geográficas, mas muito mais com as fronteiras existenciais e imaginárias e com a necessidade de defender obsessivamente uma forma de compreensão da identidade (AGIER, 2015, p. 41), discurso tão presente no mundo atual. Esquece-se que a identidade de quem quer que seja só pode ser construída na relação com o outro. Em certo sentido, não há identidade como algo dado, delimitado; ela é sempre é construída nas relações complexas de subjetividades que se relacionam, se movimentam e se desafiam.

Desta forma, em qualquer época e lugar, os processos migratórios colocam em xeque o desafio permanente - às vezes doloroso - vivido pelas pessoas de construírem suas identidades numa rede imbricada de intersubjetividades. Esse processo se torna mais difícil quando as razões que levam as pessoas a migrarem estão relacionadas com a guerra, com a violência, com a perseguição e com a perda de familiares e de pessoas próximas.

A especificidade dos fluxos migratórios nos últimos anos desafia a própria modernidade que sempre alardeou o seu slogan de igualdade, fraternidade e liberdade. Além disso, os fluxos migratórios atuais, em certo sentido, elaboram uma globalização de baixo que acaba se tornando uma contraglobalização:

nesse sentido, as migrações internacionais revelam a porosidade dos confins nacionais, a seletividade das benesses da modernidade; expressam existência de uma globalização de baixo, ou seja, das pessoas comuns, das famílias, de suas redes de relações que reagem a uma localização imposta em busca de um futuro melhor... (TEDESCO, 2012, p. 27).

Os migrantes, ao seu modo e com todas as contradições possíveis presentes nas suas lutas pela sobrevivência, com sua resistência à globalização do alto, estão apontando para outro tipo de globalização que leve em conta as necessidades e os dramas dos de baixo: pessoas, famílias e grupos humanos envolvidos no processo forçado de migração.

Os movimentos migratórios contemporâneos revelam os paradoxos desse processo mais amplo. A exclusão e a indiferença, que sempre foram características da globalização do alto, se apresentam agora com novos nuances justamente na forma como os países lidam com os migrantes. 
Se o migrante é aceito como força de trabalho barata que interessa às indústrias, ele é rejeitado quando reivindica moradia, educação, saúde e políticas públicas universais. Exclusão social e indiferença são dois lados de uma mesma moeda. Ao mesmo tempo em que o migrante é incluído como força de trabalho, é excluído como sujeito de direitos e valores. Ao mesmo tempo que se estabelecem políticas limitadas de acolhimento, cada vez mais se dissemina nas sociedades a indiferença com as pessoas dos migrantes, atitude que se expressa de várias formas, inclusive em suas formas agressivas como é o caso da xenofobia.

Qualquer tentativa de compreender os fluxos migratórios precisa levar em conta a lógica de uma globalização excludente que impera no mundo; ao mesmo tempo, não é possível compreender a globalização sem considerar as causas, as dinâmicas e as consequências desses fluxos migratórios. Embora crie diversas formas de barreiras aos fluxos migratórios, esse modelo de organização global da economia necessita dos mesmos para a sua continuidade. A globalização do alto não só é causa das migrações, mas também precisa delas para garantir sua dinâmica da exclusão e da desigualdade no interior das próprias fronteiras dos países ricos.

\section{Francisco e o tema dos migrantes na homilia de Lampedusa}

Em 24 de setembro de 2015, na visita ao Congresso dos Estados Unidos, Francisco apresentou-se como filho de imigrantes:

Nos últimos séculos, milhões de pessoas chegaram a esta terra perseguindo o sonho de construírem um futuro em liberdade. Nós, pessoas deste continente, não temos medo dos estrangeiros, porque outrora muitos de nós éramos estrangeiros. Digo-vos isto como filho de imigrantes, sabendo que também muitos de vós sois descendentes de imigrantes.

Desde o início do ministério de Francisco, o tema das migrações ${ }^{3}$ e o drama dos refugiados têm sido uma constante em seus pronunciamentos. Foi na homilia em 8 de julho de 2013, numa celebração da missa realizada na

\footnotetext{
${ }^{3} \mathrm{O}$ tema das migrações não faz parte apenas dos discursos de Francisco, mas também de suas ações. Em $1^{\circ}$ de janeiro de 2017, Francisco criou um novo Dicastério (para o Serviço do Desenvolvimento Humano Integral), que reúne a partir de então o Dicastério Justiça e Paz, o Conselho Cor Unum, a Pastoral dos Migrantes e Itinerantes, e a Pastoral para os Operadores da Saúde. Uma das seções desse novo Dicastério tem a incumbência de tratar especificamente das ações em torno da questão migratória. Foi nomeado para coordenador dessa seção o padre Fabio Baggio, membro da Congregação dos Missionários de São Carlos, a qual tem como carisma o trabalho com os migrantes e refugiados. Essa seção está vinculada diretamente a ele. A esse respeito, ver o primeiro parágrafo da Mensagem Para o Dia Mundial do Migrante e do Refugiado 2018.
} 
cidade de Lampedusa ${ }^{4}$, destino de sua primeira viagem como Papa, que Francisco disse que sua visita era um gesto de solidariedade, mas também uma tentativa de despertar as consciências para que naufrágios de navios com migrantes oriundos do norte da África não se repetissem. $\mathrm{O}$ tom da mensagem de Francisco era de denúncia: “Estes nossos irmãos e irmãs procuravam sair de situações difíceis, para encontrarem um pouco de serenidade e de paz; procuravam um lugar melhor para si e suas famílias, mas encontraram a morte".

Referindo-se aos migrantes que morrem no caminho de luta pela vida, Francisco perguntava: "Quem é o responsável pelo sangue destes irmãos e irmãs? Ninguém! Todos nós respondemos assim: não sou eu, não tenho nada a ver com isso; serão outros, eu não, certamente". O bispo de Roma coloca um problema que é uma constante quando se pensa, hoje, na questão da migração: a indiferença em relação a esse fenômeno. É o que Bauman aponta quando se refere à forma como a opinião pública e a própria mídia tratam esse tema: estamos nos aproximando do "ponto de 'fadiga da tragédia dos refugiados'" (BAUMAN, 2017, p. 8). Estamos ficando insensíveis ao drama dessas pessoas porque estamos cansados de vê-las à nossa porta e saber que permanecem a exigir de nós atitudes solidárias. Passamos da estranheza, atitude inicial diante de fatos dessa natureza, para a indiferença que nasce da insensibilidade.

Essa insensibilidade, segundo Francisco leva à "globalização da indiferença" (Lampedusa) ${ }^{5}$. A indiferença se generaliza no que diz respeito ao sofrimento do outro, à condição de precariedade do outro, já que o "sofrimento do outro, não nos diz respeito, não nos interessa, não é responsabilidade nossa!" (Lampedusa). E negação dos valores morais mais elementares que nos leva a ignorar o outro, a torná-lo invisível, como se não existisse concretamente.

Para Francisco, a indiferença tem como decorrência a incapacidade de chorar diante do sofrimento do outro e de ser solidário. Para ele, essa insensibilidade é a face da globalização, uma globalização da indiferença, que exclui aqueles que não interessam e que são um "incômodo" (Lampedusa). Esse é um dos aspectos culturais da globalização: estimula o descaso com relação àqueles que exigem de nós a solidariedade e o respeito.

Essa globalização da indiferença tirou-nos a capacidade de chorar, de sofrer com os outros. Ela instaura uma subjetividade desinteressada, descomprometida, insensível, com aqueles que são considerados desnecessários, inúteis.

\footnotetext{
${ }^{4}$ Lampedusa é uma ilha italiana localizada no Mediterrâneo. Tem sido uma das principais portas de entrada de migrantes para a Europa. De agora em diante, todas as vezes que nos referirmos a essa homilia usaremos a expressão "Lampedusa".

${ }^{5}$ A expressão "globalização da indiferença" aparece quatro vezes, e a palavra "indiferença" aparece sete vezes na homilia, que tem duas páginas e meia.
} 
É uma subjetividade que se transforma num subjetivismo, intimismo, que nos descola da realidade exterior (ARDUINE, 2002, p. 23).

O tema da indiferença, ou da globalização da indiferença, é recorrente em diversos documentos de Francisco. Exemplos disso são a Carta Encíclica Laudato Si' e a Exortação Apostólica Evangelii Gaudium (EG). Nesta ele critica esse tipo de globalização:

Para se poder apoiar um estilo de vida que exclui os outros, ou mesmo entusiasmar-se com este ideal egoísta, desenvolveu-se uma globalização da indiferença. Quase sem nos dar conta, tornamo-nos incapazes de nos compadecer ao ouvir os clamores alheios, já não choramos à vista do drama dos outros, nem nos interessamos por cuidar deles, como se tudo fosse uma responsabilidade de outrem, que não nos incumbe (EG, n. 54).

Na Laudato $\mathrm{Si}^{\prime}$ (LS), referindo-se ao aumento do número de migrantes, ele afirma que

infelizmente, verifica-se uma indiferença geral perante estas tragédias, que estão acontecendo agora mesmo em diferentes partes do mundo. A falta de reações diante destes dramas dos nossos irmãos e irmãs é um sinal da perda do sentido de responsabilidade pelos nossos semelhantes, sobre o qual se funda toda a sociedade civil (LS, n. 25).

A homilia de Lampedusa é, portanto, uma denúncia da globalização da indiferença que tem uma incidência tanto nas macroestruturas que hoje causam os deslocamentos forçados, mas também na nossa vida pessoal ao configurar um modo de vida pautado pelo descanso e pela insensibilidade diante das vítimas dos fluxos migratórios.

\section{Francisco e as Mensagens do Dia Mundial do Migrante e do Refugiado ${ }^{6}$}

Ao ler os textos de Francisco é preciso ter em conta que eles têm um perfil pastoral bastante acentuado. São textos pastorais, sem deixar de serem intensos e contundentes do ponto de vista teológico. É com essa perspectiva que queremos examinar as Mensagens do Dia Mundial do Migrante e do Refugiado escritas por Francisco desde o primeiro ano de seu ministério.

Desde Paulo VI, é costume que os Papas publiquem, por ocasião do Dia Mundial do Migrante e do Refugiado, uma mensagem a respeito do tema das migrações ${ }^{7}$. Desde 1985, com João Paulo II, tem sido costume a publicação de uma mensagem por ocasião desse dia.

\footnotetext{
${ }^{6}$ Nesta parte do artigo, os textos utilizados e que não contêm citações específicas são das Mensagens do Dia Mundial do Migrante e do Refugiado.

${ }^{7}$ A primeira mensagem de Paulo VI foi através do rádio em 1963.
} 
A seguir, examinamos cada uma das Mensagens de Francisco, de 2014 a 2018, com a finalidade de apresentar o conteúdo central dessas Mensagens, para depois, na última parte, identificar os seus eixos principais.

Mensagem para 2014 - "Migrantes e refugiados: rumo a um mundo melhor" - publicada em 05/08/2013.

Antes de apresentar o tema escolhido por ele para o Dia Mundial do Migrante e do Refugiado de 2014, Francisco apresenta o contexto a partir do qual ele fez essa escolha: vivemos hoje um conjunto de "processos de interdependência mútua e interação em um nível global". Esse é o quadro mais geral no qual Francisco situa o tema "Migrantes e refugiados: rumo a um mundo melhor". Para ele, esse mundo melhor se refere "à busca de um desenvolvimento autêntico e integral, para poder agir de tal modo que haja condições de vida digna para todos".

Para Francisco, no âmbito do fenômeno migratório o que é preocupante são as migrações forçadas, sobretudo pela guerra e outras formas de violência, o tráfico humano e o trabalho escravo. Apesar desses riscos, segundo a mensagem, o que fazem os migrantes e refugiados enfrentarem essa situação com confiança e esperança é "o desejo de um futuro melhor não só para si mesmos, mas também para as suas famílias e para os entes queridos".

À pergunta "o que significa a criação de um 'mundo melhor'?", Francisco aponta três características:

- "Essa expressão não se refere ingenuamente a conceitos abstratos ou a realidades inatingíveis, mas se dirige à busca de um desenvolvimento autêntico e integral, para poder agir de tal modo que haja condições de vida digna para todos".

"A realidade das migrações, com as dimensões que assume na nossa época de globalização, precisa ser tratada e gerida de uma maneira nova, justa e eficaz, o que exige, acima de tudo, uma cooperação internacional e um espírito de profunda solidariedade e compaixão".

- "olhando para a realidade dos migrantes e refugiados, há um terceiro elemento que eu gostaria de destacar neste caminho de construção de um mundo melhor: a superação de preconceitos e de pré-compreensões, ao considerar as migrações".

Num primeiro momento, Francisco recorre a um dos temas centrais do Ensino Social da Igreja Católica, ao dizer que a busca por um mundo melhor passa pelo "desenvolvimento autêntico e integral" (PCJP, 2006, p. 213), um desenvolvimento que atenda a todas as pessoas, e não apenas a uma minoria, e ao mesmo tempo atenda a todas as dimensões da pessoa (Populorum Progressio, n. 14). Em seguida, o Papa afirma que a realidade das migrações precisa ser gerida de outra forma, pautada pela solidarie- 
dade e pela compaixão. A própria gestão das fronteiras, que privilegia a circulação de mercadorias e bloqueia o movimento de pessoas, tem como resultado novos mapas que marginalizam o migrante. As fronteiras, que deveriam ser flexíveis, tornam-se verdadeiras barreiras aos movimentos migratórios forçados. Por último, o Papa fala na necessidade de superar os preconceitos e pré-compreensões em torno do migrante e dos movimentos migratórios. Esses preconceitos permeiam as estruturas (leis e aparatos institucionais) e as consciências das pessoas ao criar certos estereótipos do migrante, como aquele que tira o emprego, e como aquele que é perigo e ameaça à segurança dos nacionais. Para Francisco, a criação de um mundo melhor supõe, portanto, uma mudança cultural profunda que rompa com os preconceitos e com as pré-compreensões no que se refere aos migrantes.

As características desse "mundo melhor" apresentadas por Francisco, como é possível observar, trazem na sua lógica a denúncia de tudo o que impede a sua realização. Desta forma, na sua primeira mensagem sobre o Dia do Migrante e do Refugiado, o posicionamento do Papa não só aponta para a necessidade de mudanças sociais - nacionais e mundiais - que alterem significativamente o modo como os migrantes são tratados, mas também recorda à Igreja que esta é "chamada a ser o Povo de Deus que abraça todos os povos, e leva a todos os povos o anúncio do Evangelho, pois no rosto de cada pessoa está estampado o rosto de Cristo". Segundo Francisco, para a Igreja a realidade dos migrantes e refugiados é oportunidade para que a comunidade cristã contribua com a construção de uma sociedade mais justa e fraterna.

Mensagem para 2015 - "Igreja sem fronteiras, mãe de todos" - publicada em 03/09/2014.

Francisco inicia o texto fazendo referência à "solicitude (de Jesus), especialmente pelos mais vulneráveis e marginalizados, [que] a todos convida a cuidar das pessoas mais frágeis e reconhecer o seu rosto de sofrimento, sobretudo nas vítimas das novas formas de pobreza e escravidão". Esse é o horizonte em que Francisco situa o tema escolhido: "Igreja sem fronteiras, mãe de todos".

O tema acima leva Francisco a afirmar que

a Igreja sem fronteiras, mãe de todos, propaga no mundo a cultura do acolhimento e da solidariedade, segundo a qual ninguém deve ser considerado inútil, intruso e descartável. A comunidade cristã, se viver efetivamente a sua maternidade, nutre, guia e aponta o caminho, acompanha com paciência, solidariza-se com a oração e as obras de misericórdia.

O tema "da Igreja sem fronteiras, mãe de todos" também está presente na Exortação Apostólica Evangelii Gaudium:

Os migrantes representam um desafio especial para mim, por ser Pastor duma Igreja sem fronteiras que se sente mãe de todos. Por isso, exorto os países a 
uma abertura generosa, que, em vez de temer a destruição da identidade ${ }^{8}$ local, seja capaz de criar novas sínteses culturais (EG, n. 210).

A ideia de uma Igreja sem fronteiras refere-se não só ao espaço de sua atuação, que deve ultrapassar as fronteiras geográficas, mas também ao fato de que a Igreja tem que ser uma Igreja acolhedora, aberta a todos, uma "Igreja de portas abertas" (EG, n. 46 e 47). Esse tema está bastante conectado com o tema da "Igreja em saída" também presente na Evangelii Gaudium (n. 17). Ao recorrer ao tema de uma Igreja sem fronteiras, que é mãe de todas as pessoas e que deve ser acolhedora e misericordiosa, Francisco propõe um mundo que seja mais acolhedor e humano.

Na mensagem para 2015, Francisco chama a atenção para o "caráter multicultural das sociedades de hoje" que coloca novas exigências para a Igreja Católica no que diz respeito à sua atuação levando-a a assumir "novos compromissos de solidariedade, comunhão e evangelização". Esse caráter multicultural exige o respeito à diversidade cultural e a instauração do que o Papa denomina de "cultura do encontro", na qual as pessoas possam garantir a sua identidade cultural em diálogo com os diversos aspectos culturais das sociedades que os acolhem.

Para o Papa, os movimentos migratórios, além de trazerem à tona os dramas mais profundos da humanidade, também denunciam as condições desumanas presentes em sociedades que se negam a acolher o estrangeiro e, ao mesmo tempo, exigem uma nova lógica social fundada na igualdade e na solidariedade.

A "cultura do encontro numa harmonia pluriforme" (EG, n. 220), defendida por Francisco, é caminho para a construção de uma sociedade na qual nacionais e migrantes sejam acolhidos para viver de forma digna e respeitosa. No pensamento do Papa, a noção de cultura do encontro tem o seu contraponto na cultura auto-referencial, predominante no mundo capitalista. A utilização dessa noção por Francisco, tanto na Mensagem para 2015, como também na própria Evangelii Gaudium, tem suas raízes no documento de Aparecida, em cuja redação o cardeal Bergoglio teve uma participação decisiva. A esse respeito, Emilce Cuda afirma que

em continuidade com o analisado no Documento de Aparecida - do qual o cardeal argentino Jorge Bergoglio tomou parte, e em cuja redação teve uma participação significativa -, podemos comprovar que na Exortação Evangelii Gaudium de Papa Francisco também se diferenciam - nas entrelinhas - dois tipos de cultura, a cultura do encontro e a cultura auto-referencial $(2016, \text { p. } 247)^{9}$.

\footnotetext{
${ }^{8}$ Como veremos a seguir, o tema da identidade é uma constante nas Mensagens de Francisco. ${ }^{9}$ A expressão auto-referencial tem sido muito utilizada por Francisco para criticar uma mentalidade muito comum, hoje, de um egoísmo muito exacerbado que coloca o indivíduo como centro da compreensão da vida. A esse respeito ver EG 8, 94 e 95 e LS 204 e 208.
} 
Mensagem para 2016 - "Os emigrantes e refugiados interpelam-nos. A resposta do Evangelho da misericórdia" - publicada em 12/09/2015.

Na Mensagem de 2016, Francisco parte de uma constatação preliminar: o fenômeno da migração está acontecendo em todas as áreas do planeta. Esse fato, segundo ele, interpela as comunidades nos diversos países que são escolhidos como destinos pelos migrantes. Ao mesmo tempo, esses fatos obrigam os diversos países e as pessoas a repensarem o seu modo de entender os migrantes e refugiados, as suas reivindicações e, sobretudo, o seu potencial de diversidade cultural. O fenômeno migratório dá "um choque de realidade" nas concepções tradicionais, que veem a diversidade apenas a partir do horizonte de quem pensa e reflete sobre ela. Aqui está, certamente, um dos grandes questionamentos feitos ao Ocidente pela migração: ela mostra que a ideia de diversidade cultural, no Ocidente, tem que ser revista a partir das interpelações do Outro, do estrangeiro.

Os dramas vividos pelos migrantes e refugiados, tanto nos países de origem, como nas fronteiras e nos países que os acolhem, revela a incapacidade desses países de estabelecerem políticas de regulação do processo migratório que possam ser consideradas condizentes com a dignidade humana. De modo geral, ainda não se consolidou uma política de gestão das migrações que esteja em consonância com os direitos humanos.

A partir dessa constatação, Francisco chega a afirmar que os fluxos migratórios fazem parte de um contexto maior de estruturas socioeconômicas. Por isso, segundo ele, é necessário sair da precariedade de programas emergenciais de acolhida para avançar para o estabelecimento de programas que levem em conta as causas e as consequências do fluxo migratório. Nesse sentido, a proposta de regulação das migrações, feita por Francisco, tem também uma perspectiva estrutural coerente com a sua análise do fenômeno; se o fenômeno migratório se funda em causas estruturais, as políticas de regulação também têm que ser de cunho estrutural.

A questão da identidade é apontada por Francisco como uma questão importante:

Neste momento da história da humanidade, fortemente marcado pelas migrações, a questão da identidade não é uma questão de importância secundária. De fato, quem emigra é forçado a modificar certos aspectos que definem a sua pessoa e, mesmo sem querer, obriga a mudar também quem o acolhe.

Embora, no caso dos migrantes, a questão da identidade torna-se muitas vezes razão de muito sofrimento, no caso daqueles que os acolhem também a presença de grupos étnicos diferentes torna-se um desafio do ponto de vista cultural, social e econômico. Assim, a presença dos migrantes "interpela seriamente as diferentes sociedades que os acolhem". Para Francisco, diante de tais situações, a resposta da Igreja é a misericórdia que é dom 
de Deus, mas é também caminho para solidificar a solidariedade para com o próximo.

Por isso, o Papa propõe olhar para os migrantes muito além de "sua condição de regularidade ou irregularidade, mas sobretudo como pessoas que, tuteladas em sua dignidade, podem contribuir para o bem-estar e o progresso de todos".

Mensagem para 2017 - "Migrantes de menor idade, vulneráveis e sem voz" - publicada em 08/09/2016.

A Mensagem para 2017 tem como preocupação central os migrantes de menor idade, parcela significativa e bastante vulnerável dos contingentes de migrantes. O Papa começa referindo-se ao lugar privilegiado das crianças no ensinamento de Jesus. $O$ critério fundamental presente da mensagem evangélica é o acolhimento (Mc 9,37).

Segundo o Papa, as crianças migrantes "são três vezes mais vulneráveis porque de menor idade, porque estrangeiros e porque indefesas - quando, por vários motivos, são forçadas a viver longe de sua terra natal e separadas do carinho familiar". Alguns dados do UNICEF ajudam a entender a situação descrita pelo Papa: "200 mil crianças desacompanhadas pediram asilo em 80 países em 2015-2016; 100 mil crianças desacompanhadas foram presas na fronteira entre os Estados Unidos e o México em 2015-2016; 170 mil crianças desacompanhadas pediram asilo na Europa em 2015-2016; crianças desacompanhadas e separadas de suas famílias representaram 92\% de todas as crianças que chegaram à Itália por mar em 2016. As crianças representam aproximadamente $28 \%$ das vítimas do tráfico globalmente" ${ }^{\prime 10}$.

Para o Papa, as crianças migrantes "são os primeiros a pagar o preço oneroso da emigração, provocada quase sempre pela violência, a miséria e as condições, fatores estes que se associam também à globalização nos seus aspectos negativos".

Na perspectiva de Francisco, a resposta a essa realidade passa pela tomada de consciência de que "o fenômeno migratório não é alheio à história da salvação; pelo contrário, faz parte dela". Em segundo lugar, para o Papa "esse fenômeno constitui um sinal dos tempos"1, um sinal que fala da obra providencial de Deus na história e na comunidade humana".

Francisco afirma que é necessário apostar na proteção, na integração e em soluções duradouras. Para isso, propõe três medidas: garantir proteção e defesa aos menores migrantes; "trabalhar pela integração das crianças e

\footnotetext{
${ }^{10}$ https://www.unicef.org/brazil/pt/media_36161.html. Acesso em 28/09/17.

${ }^{11} \mathrm{O}$ itálico é do próprio documento.
} 
adolescentes migrantes"; adotar soluções duradouras que levem em conta as causas reais da migração.

Mensagem para 2018 - "Acolher, proteger, promover e integrar os migrantes e refugiados" - publicada em 15/08/2017.

Na Mensagem para o Dia Mundial do Migrante e do Refugiado de 2018, o Papa retoma a sua visita a Lampedusa, afirmando que esta foi um sinal dos tempos. Em seguida, afirma que a Igreja tem a tarefa de acolher, em toda a sua experiência migratória, cada "ser humano forçado a deixar a sua pátria à procura dum futuro melhor".

A Mensagem está estruturada de acordo com quatro verbos: acolher, proteger, promover e integrar. O Papa retoma o conteúdo do seu discurso aos participantes do Fórum Internacional sobre Migrações e Paz, em 21 de fevereiro de 2017. Nesse discurso, Francisco afirma que a resposta aos desafios dos fluxos migratórios deve se articular nesses quatro verbos ${ }^{12}$.

Acolher significa, de acordo com a Mensagem, "oferecer a migrantes e refugiados possibilidades mais amplas de entrada segura e legal nos países de destino". E as medidas possíveis apontadas vão desde a criação de condições concretas de acolhida, nos países receptores de migrantes, até a adoção de políticas públicas que tenham a pessoa humana como centro dessas políticas.

Proteger se traduz "numa ampla série de ações em defesa dos direitos e da dignidade dos migrantes e refugiados, independentemente da sua situação migratória". A proteção dessas pessoas deve ser traduzida em medidas efetivas que visem garantir os direitos fundamentais: ao trabalho, à moradia, à alimentação, à saúde e à seguridade social. Nesse momento da Mensagem, o Papa volta a insistir na necessidade de garantir proteção adequada às crianças migrantes e refugiadas.

Promover significa "empenhar-se por que todos os migrantes e refugiados, bem como as comunidades que os acolhem, tenham condições para se realizar como pessoas em todas as dimensões que compõem a humanidade querida pelo Criador". Nesse aspecto, Francisco chama a atenção para duas dimensões que precisam ser levadas em conta: a dimensão religiosa e a dimensão sócio-laboral. Segundo ele, os países que acolhem devem garantir a liberdade religiosa e o acesso ao trabalho, para que os migrantes e refugiados possam viver com dignidade.

\footnotetext{
${ }^{12}$ Nesse discurso, Francisco apresenta três deveres "em relação aos irmãos e irmãs que, por diferentes motivos, são forçados a deixar a própria terra de origem: um dever de justiça, de civilização e de solidariedade" (http://w2.vatican.va/content/francesco/pt/speeches/2017/ february/documents/Papa-francesco_20170221_forum-migrazioni-pace.html).
} 
Integrar "situa-se no plano das oportunidades de enriquecimento intercultural geradas pela presença de migrantes e refugiados. A integração não é uma 'assimilação', que leva a suprimir ou esquecer a própria identidade cultural". O Papa tem consciência de que o processo de integração é complexo, e afeta a sociedade e a cultura. Para ele, o processo de integração é uma oportunidade para que as diversas dádivas manifestadas por Deus no meio das pessoas possam ser disponibilizadas, inclusive aos migrantes e refugiados. Os países que os acolhem devem criar condições para que eles possam contribuir com a riqueza cultural local.

\section{Aspectos centrais do pensamento de Francisco presentes nas Mensagens}

A migração, em qualquer época e lugar, coloca em xeque a própria condição humana: conviver com as outras pessoas supõe conviver com as diferenças, sem tornar o diferente um estranho, garantindo o respeito aos princípios éticos e possibilitando a convivência humana respeitosa e fraterna. $\mathrm{O}$ fenômeno migratório a que assistimos hoje, com todas as suas múltiplas causas, está questionando tanto o modelo de globalização, como também os modelos utilizados pelos países ricos para entender esses processos.

Nos últimos anos, Francisco tem sido a liderança que mais tem insistido no tema dos migrantes e dos refugiados, e que tem assumido uma postura crítica frente à forma como os países tem gerenciado os fluxos migratórios. O próprio Bauman reconhece que o Papa tem sido uma "das pouquíssimas figuras públicas a nos alertar acerca dos perigos de seguir o gesto de Pôncio Pilatos" (BAUMAN, 2017, p. 25) com relação aos dramas vividos pelos migrantes e refugiados.

No seu discurso aos participantes do Fórum Internacional sobre Migrações e $\mathrm{Paz}^{13}$, Francisco afirmou que "migrar é expressão da aspiração intrínseca à felicidade, própria de cada ser humano". No entanto, naquela ocasião ele reconhecia também que, neste terceiro milênio, os fluxos migratórios atingem quase todo o planeta e, na maioria das vezes, "trata-se de deslocamentos forçados, causados por conflitos, calamidades naturais, perseguições, mudanças climáticas, violências, pobreza extrema e condições de vida indignas".

O pensamento de Francisco quanto à crise migratória não apresenta só um diagnóstico, mas também apresenta diretrizes gerais para responder aos desafios da onda migratória. A reflexão que fizemos em torno das

\footnotetext{
${ }^{13}$ http://w2.vatican.va/content/francesco/pt/speeches/2017/february/documents/Papa-francesco_20170221_forum-migrazioni-pace.html.
} 
Mensagens para o Dia Mundial do Migrante e do Refugiado apresenta os principais aspectos do pensamento de Francisco sobre o tema das migrações.

Um primeiro aspecto é aquele que diz respeito à compreensão de Francisco a respeito da realidade global. Para Francisco a realidade global, no tempo presente, pode ser caracterizada por um conjunto de "processos de interdependência e interação em um nível global", como ele expressou na Mensagem para 2014. No número 137 da Laudato Si', Francisco reconhecia essa interdependência e interação:

Dado que tudo está intimamente relacionado, e que os problemas requerem um olhar que tenha em conta todos os aspectos da crise mundial, proponho que nos detenhamos [...] sobre os diferentes elementos duma ecologia integral, que inclua claramente as dimensões humanas e sociais (LS, n. 137).

A migração, como qualquer outro processo no mundo globalizado, só pode ser compreendida dentro da dinâmica mais global de interdependência. Com a complexificação das relações entre os países no atual estágio de globalização, qualquer fenômeno só pode ser entendido nesse contexto. O entendimento do processo migratório passa pela compreensão da inter-relação entre a crise migratória e outras crises presentes no mundo.

Um segundo aspecto diz respeito à ideia de um mundo melhor. Essa ideia se apresenta nos discursos de Papa como uma utopia, como uma alternativa à situação que vivemos. Tanto na Evangelii Gaudium, como na Laudato Si', essa expressão está presente (LS, n. 134; EG, n. 183). Na Mensagem para 2014, Francisco afirma que a expressão mundo melhor não se refere a conceitos abstratos ou realidades inatingíveis.

Para o Papa, o mundo melhor se refere à busca do desenvolvimento autêntico e integral que propicie vida digna para todas as pessoas, à existência da cooperação internacional baseada na solidariedade e compaixão, e à superação de preconceitos e pré-compreensões.

Uma nova gestão da migração é o terceiro aspecto do pensamento de Francisco sobre as migrações. Como vimos na Mensagem para 2014, Francisco afirma que a realidade das migrações "precisa ser tratada e gerida de uma maneira nova, justa e eficaz". Isso supõe que, antes de tudo, seja levada em conta a dimensão estrutural dos movimentos migratórios e a perspectiva de um desenvolvimento que atenda de fato às necessidades das pessoas.

Essa nova gestão da migração exige a criação de políticas públicas voltadas para oferecer as condições reais de vida digna - trabalho, moradia, saúde e demais direitos - para os migrantes e refugiados, e também a criação de uma nova consciência que estimule a solidariedade com os migrantes, refugiados e com os estrangeiros de modo geral. Nesse segundo caminho, os sistemas educacionais, as Igrejas e religiões, e os meios de comunicação 
têm um papel fundamental, no sentido de disseminar valores como respeito ao diferente e solidariedade com os que mais sofrem.

A globalização da indiferença é o quarto aspecto do pensamento de Francisco sobre a migração. Ao tratar do tema, ele tem denunciado em vários momentos aquilo que ele denomina de globalização da indiferença. Essa globalização da indiferença não é apenas um sistema de organização da vida baseada nas inter-relações de países. É também uma cultura que estimula as pessoas a se pautarem apenas pelos seus interesses pessoais alimentando um sentimento de indiferença diante dos outros, sobretudo daqueles que sofrem. Como afirma o Papa, "habituamo-nos ao sofrimento do outro, não nos diz respeito, não nos interessa, não é responsabilidade nossa!" (Lampedusa).

A globalização da indiferença instaura relações de estranhamento e de distanciamento entre as pessoas. Atualmente os migrantes são as maiores vítimas dessa dinâmica da indiferença. Diante dos sofrimentos e dramas vividos pelos migrantes, há uma cultura da indiferença que nos faz ficar alheios a essa realidade.

A crítica que Francisco faz a essa globalização questiona não só o modelo, que tem implicações nas diversas esferas sociais, mas também a forma como reagimos a essa dinâmica: frequentemente nos esquecemos que somos parte de uma família humana e que "o urgente desafio de proteger a nossa casa comum inclui a preocupação de unir toda a família humana na busca de um desenvolvimento sustentável e integral, pois sabemos que as coisas podem mudar" (LS, n. 13).

Não podemos esquecer que "sofremos no corpo e na mente os efeitos da 'globalização da indiferença', do mal-estar da civilização" (CARVALHO, 2016, p. 116). A globalização da indiferença, que hoje se manifesta de forma mais lancinante diante do fenômeno migratório, diz respeito a todos nós.

\section{Considerações finais}

A reflexão que fizemos sobre as Mensagens para o Dia Mundial do Migrante e do Refugiado revela que Francisco tem consciência de que os fluxos migratórios não podem ser vistos como processos isolados, sem interação com as estruturas da globalização.

Perpassa os textos das Mensagens a ideia de que a análise dos fluxos migratórios não pode ser vista apenas nas suas causas específicas ou consequências imediatas; é necessário compreendê-los como parte de um contexto maior e mais complexo, que está relacionado com o quadro mais geral criado pelos próprios países ricos em sua trajetória de colonização. 
Por trás e sob os movimentos migratórios, temos uma denúncia silenciosa, mas não menos escancarada, da própria relação dos países ricos com os países pobres, e do próprio modelo de estruturação econômica. Por isso as Mensagens de Francisco sobre as migrações são bastante relevantes tanto para a compreensão do fenômeno migratório atual, como também para a própria Igreja Católica. Para ele, a Igreja sem fronteiras necessita discernir nas migrações de hoje um grande sinal dos tempos para rever a sua própria atuação.

As Mensagens escritas por Francisco para o Dia Mundial do Migrante e do Refugiado revelam um profundo conhecimento das condições estruturais que causam a intensificação dos movimentos migratórios atuais. Ao mesmo tempo, as Mensagens apontam para medidas, seja por parte dos governos, da sociedade civil e da própria Igreja Católica, que visam atingir o âmago estrutural do processo econômico global presente no mundo atual.

Em síntese, podemos afirmar que a denúncia que Francisco faz a respeito das dinâmicas dos fluxos migratórios presentes manifesta duas atitudes que precisam ser resgatadas pela Igreja Católica: em primeiro lugar, a indignação ética, e, em segundo lugar, a profecia. A realidade vivida hoje pelos migrantes e refugiados é uma das muitas oportunidades para a Igreja Católica assumir essas atitudes, que podem dar-lhe mais vida e mais jovialidade no anúncio do Reino de Deus.

\section{Referências}

AGIER, M. Migrações, descentramento e cosmopolitismo: uma antropologia das fronteiras. Maceió-São Paulo: Edufal-Ed.Unesp, 2015.

ARDUÍNE, J. Antropologia: ousar para reinventar a humanidade. São Paulo: Paulus, 2002.

BAUMAN, Z. Estranhos à nossa porta. Rio de Janeiro: Zahar, 2017.

CARVALHO, E. A. Perspectiva interdisciplinar inerente à Encíclica. In: PASSOS, J. D. (Org.). Diálogos no interior da casa comum: recepções interdisciplinares sobre a Encíclica Laudato Si'. São Paulo: Educ-Paulus, 2016.

CUDA, E. Para ler a Francisco: teología, ética e política. Buenos Aires: Manancial, 2016.

FRANCISCO. Exortação Apostólica Evangelii Gaudium. São Paulo: Paulinas, 2013. homília em Lampedusa 08/07/2013. Disponível em: <http://w2.vatican.va/content/ francesco/pt/homilies/2013>. Acesso em: 21 abr. 2017.

. Mensagem do Papa Francisco para o Dia Mundial do Migrante e do Refugiado (2014). Disponível em: < http://w2.vatican.va/content/francesco/pt/messages/ migration>. Acesso em: 27 abr. 2017. 
. Mensagem do Papa Francisco para o Dia Mundial do Migrante e do Refugiado (2015). Disponível em: <http://w2.vatican.va/content/francesco/pt/messages/ migration>. Acesso em: 27 abr. 2017.

. Carta Encíclica Laudato Si' sobre o cuidado da casa comum. São Paulo: Paulus-Loyola, 2015.

- Mensagem do Papa Francisco para o Dia Mundial do Migrante e do Refugiado (2016). Disponível em: < http://w2.vatican.va/content/francesco/pt/messages/ migration>. Acesso em: 27 abr. 2017.

- Mensagem do Papa Francisco para o Dia Mundial do Migrante e do Refugiado (2017). Disponível em: <http://w2.vatican.va/content/francesco/pt/messages/ migration>. Acesso em: 27 abr. 2017.

HIRST, P. e THOMPSON, G. Globalização em questão: a economia internacional e as possibilidades de governabilidade. Petrópolis: Vozes, 1998.

PAULO VI, Papa. Carta Encíclica Populorum Progressio. Roma: 1967. Disponível em: $<$ http://w2.vatican.va/content/paul-vi/pt/encyclicals>. Acesso em: 27 abr. 2017.

PCJP - PONTIFÍCIO CONSELHO “JUSTIÇA E PAZ". Compêndio da Doutrina Social da Igreja. 3.ed. São Paulo: Paulinas, 2006.

TEDESCO, J. C. Modernidade e migração: o estrangeiro na globalização. In: PEREIRA, G.M.S.; PEREIRA, J.R.S. Migração e globalização: um olhar interdisciplinar. Curitiba: CRV, 2012.

Artigo submetido em 09.12.2017 e aprovado em 30.04.2018.

Wagner Lopes Sanchez é doutor em Ciências Sociais (PUC-SP, 2001) e mestre em Ciências Sociais (PUC-SP, 1989), é professor do Programa de Pós-Graduação em Ciência da Religião e no Instituto São Paulo de Estudos Superiores (ITESP). Orcid.org/0000-0002-2138-4125. E-mail: wagnersanchez@uol.com.br

Endereço: Rua Professor Simões Magro, 12

Vila Medeiros.

02217-030 São Paulo - SP 